\title{
Heterogeneous Catalysis for Environmental Remediation
}

\author{
Xiaoguang Duan * (iD) and Shaobin Wang * \\ Department of Chemical Engineering, Curtin University, GPO Box U1987, Bentley, WA 6845, Australia \\ * Correspondence: xiaoguang.duan@curtin.edu.au (X.D.); shaobin.wang@curtin.edu.au (S.W.); \\ Tel.: +61-8-6304-5067 (X.D. \& S.W.)
}

Received: 11 August 2017; Accepted: 15 August 2017; Published: 16 August 2017

The intensive human activities in chemical industry and environmental purification urge the development of advanced protocols for green production and waste management. In environmental science, developing highly efficient and environmentally-friendly catalytic materials and systems are very favourable approaches to green chemical synthesis and remediation of contaminated air, soil, and wastewater. Therefore, unveiling the relationship between material structure/chemistry and performances in heterogeneous catalysis would provide valuable guidance for rational catalyst design as well as addressing the challenges in potential applications in environmental science. Here, we dedicate this special issue to showcasing the recent progress in fabrication and evaluation of state-of-the-art carbon/metal catalysts for green chemistry, photocatalysis, advanced oxidation processes (AOPs), and other applications in environmental technologies.

Advanced oxidative processes have been demonstrated as a powerful technique for activating superoxides producing oxidative species (free radicals) for complete degradation of organic pollutants in aqueous systems. Wang et al. [1] synthesized magnetic carbon supported manganese oxides $\left(\mathrm{Fe}_{3} \mathrm{O}_{4} / \mathrm{C} / \mathrm{Mn}\right)$, which could effectively activate peroxymonosulfate (PMS) for phenol mineralization. The redox $\mathrm{Mn}^{4+} / \mathrm{Mn}^{3+}$ couple is the catalytic site for radical generation and the magnetic $\mathrm{Fe}_{3} \mathrm{O}_{4}$ counterpart not only serves as a support but also results in easy separation of the catalyst from the water by an external magnetic field. Zhu et al. [2] developed a Co-Fe alloy catalyst which outperformed $\mathrm{CoFe}_{2} \mathrm{O}_{4}$ for triggering PMS to evolve sulfate radicals, while the formation of Co-Fe nitride crystallites significantly improved the stability in the aqueous oxidative environment. Chen et al. [3] reported a Ce-Mg/ $/ \mathrm{Al}_{2} \mathrm{O}_{3} /$ ozone system that exhibited great oxidative efficiency for decomposition of resistant petroleum organic wastes from the petroleum refinery industry.

Chemical synthesis usually requires a green and robust catalyst to transfer hydrocarbons to target products with desired conversion efficiency, selectivity, and stability. Zhao et al. [4] synthesized a Cu-g- $\mathrm{C}_{3} \mathrm{~N}_{4}$ /activated-carbon composites to replace the toxic mercury-based catalysts for acetylene hydrochlorination which yielded a high conversion of acetylene and great selectivity of vinyl chloride. Meanwhile, the catalyst maintained superb stability in resistance to coke deposition. Lin et al. [5] discovered that sulphated tin ion-exchanged montmorillonite $\left(\mathrm{SO}_{4}{ }^{2-} / \mathrm{Sn}-\mathrm{MMT}\right)$, with both Brønsted and Lewis acid sites, could catalytically convert xylose and xylan into furfural. Chung et al. [6] revealed that the acid strength and porous structure of microporous zeolites could be manipulated to achieve selective glucose conversion to decyl glucoside.

Carbon monoxide $(\mathrm{CO})$ and nitrogen oxides $\left(\mathrm{NO}_{\mathrm{x}}\right)$ generated from industrial production and human activities are hazardous gases that would cause severe air pollution. The nanocomposites such as mesoporous $\mathrm{CuO}-\mathrm{TiO}$ nanotubes (Zedan et al. [7]) and $\mathrm{CuO}$ nanorods-reduced graphene oxide (Wang et al. [8]) were developed for catalytic oxidation of $\mathrm{CO}$ to $\mathrm{CO}_{2}$ at low temperatures. Di and co-workers [9] discovered that the thermal activation atmosphere dramatically impacted the catalytic activity of CuBTC MOF for CO oxidation. Besides, mixed metal oxides of Fe-W-Ce (Stahl et al. [10]) and $\mathrm{V}_{2} \mathrm{O}_{5}-\mathrm{WO}_{3} / \mathrm{TiO}_{2}$ (Qi et al. [11]) could be utilized for selectively converting $\mathrm{NO}_{\mathrm{x}}$ with $\mathrm{NH}_{3}$ into 
harmless $\mathrm{N}_{2}$ and water. The reduction of nitrous oxide $\left(\mathrm{N}_{2} \mathrm{O}\right)$ and oxidative dehydrogenation of ethane to ethylene could be simultaneously achieved on $\mathrm{Cr} / \mathrm{Al}_{2} \mathrm{O}_{3}$ (Zhang et al. [12]). It was also discovered that $\mathrm{N}_{2} \mathrm{O}$ could be directly decomposed on $\mathrm{Cu}-\mathrm{Zn} / \mathrm{ZuAl}_{2} \mathrm{O}_{4}$ (Zeng et al. [13]) and $\mathrm{Cu}-\mathrm{Zn} / \gamma-\mathrm{Al}_{2} \mathrm{O}_{3}$ (Zhang et al. [14]).

Developing photocatalysts for efficient utilization of solar energy would contribute to a sustainable future for the human race. Truppi et al. [15] conducted a comprehensive review of the recent progress in novel $\mathrm{TiO}_{2}$-based nanocomposites as visible-light-driven photocatalysts for versatile environmental applications. The mesoporous $\mathrm{TiO}_{2} / \mathrm{SiO}_{2}$ composites from a biotemplating method (Yan et al. [16]) and $\mathrm{TiO}_{2}$-impregnated porous silica tubes (Hayashi et al. [17]) have been demonstrated as outstanding photocatalysts for dye purification under UV irradiation. Two/three-unit hybrid nanomaterials of $\mathrm{MoS}_{2} / \mathrm{TiO}_{2}$ nanobelts (Liu et al. [18]), three-dimensional $\mathrm{WO}_{3}-\mathrm{TiO}_{2}$ nanoflowers (Lee et al. [19]) and $\mathrm{TiO}_{2} / \mathrm{RGO} / \mathrm{Ag}$ (Tian et al. [20]) were constructed for photocatalytic $\mathrm{Cr}(\mathrm{VI})$ reduction, photo-oxidation of toxic aromatic volatile compounds, and photodegradation of methylene blue, respectively. The superior photocatalytic activity of the composites compared with the single compounds was due to the enhanced light absorption, improved charge separation efficiency, and optimized band structure of the semiconductors. Photocatalysts beyond $\mathrm{TiO}_{2}$ were also explored in this special issue. Shu et al. [21] reported that immobilized $\mathrm{ZnO} / \mathrm{Vis}$ could be applied for decomposition of orange $\mathrm{G}$ in wastewater. Meng et al. [22] prepared $\mathrm{ZnCr}$ layered double hydroxides (LDHs) with salen-metal complex $(\mathrm{M}=\mathrm{Co}$ or $\mathrm{Ni}$ ) intercalation which exhibited much better photocatalytic activity than traditional LDHs. Additionally, layered perovskite $\mathrm{K}_{2} \mathrm{La}_{2} \mathrm{Ti}_{3} \mathrm{O}_{10}$ was modified with a $\mathrm{Cu}^{2+}$ iron-exchange (Pang et al. [23]) for mineralization of chlorobenzene in the presence of $\mathrm{CO}_{2}$ under simulated solar light irradiation.

Overall, this special issue covers state-of-the-art heterogeneous catalysis for applications in environmental science which would contribute to addressing technical problems for material design as well as underpinning the mechanistic insights of environmental catalysis. The guest editors would like to express their appreciation for the professional assistance from the editorial team and for the excellent research findings from all the authors which made this issue a great success.

Author Contributions: S.W. wrote the background and aims of this special issue; X.D. briefly categorized and summarized the research findings in this issue.

Conflicts of Interest: The authors declare no conflict of interest.

\section{References}

1. Wang, Y.; Xie, Y.; Chen, C.; Duan, X.; Sun, H.; Wang, S. Synthesis of Magnetic Carbon Supported Manganese Catalysts for Phenol Oxidation by Activation of Peroxymonosulfate. Catalysts 2017, 7, 3. [CrossRef]

2. Zhu, K.; Jin, C.; Klencsár, Z.; Ganeshraja, A.; Wang, J. Cobalt-iron Oxide, Alloy and Nitride: Synthesis, Characterization and Application in Catalytic Peroxymonosulfate Activation for Orange II Degradation. Catalysts 2017, 7, 138. [CrossRef]

3. Chen, C.; Chen, Y.; Yoza, B.; Du, Y.; Wang, Y.; Li, Q.; Yi, L.; Guo, S.; Wang, Q. Comparison of Efficiencies and Mechanisms of Catalytic Ozonation of Recalcitrant Petroleum Refinery Wastewater by Ce, $\mathrm{Mg}$, and Ce-Mg Oxides Loaded $\mathrm{Al}_{2} \mathrm{O}_{3}$. Catalysts 2017, 7, 72. [CrossRef]

4. Zhao, W.; Zhu, M.; Dai, B. The Preparation of Cu-g- $\mathrm{C}_{3} \mathrm{~N}_{4} /$ AC Catalyst for Acetylene Hydrochlorination. Catalysts 2016, 6, 193. [CrossRef]

5. Lin, Q.; Li, H.; Wang, X.; Jian, L.; Ren, J.; Liu, C.; Sun, R. SO ${ }_{4}{ }^{2-} /$ Sn-MMT Solid Acid Catalyst for Xylose and Xylan Conversion into Furfural in the Biphasic System. Catalysts 2017, 7, 118. [CrossRef]

6. Chung, K.-H.; Park, H.; Jeon, K.-J.; Park, Y.-K.; Jung, S.-C. Microporous Zeolites as Catalysts for the Preparation of Decyl Glucoside from Glucose with 1-Decanol by Direct Glucosidation. Catalysts 2016, 6, 216. [CrossRef]

7. Zedan, A.; Allam, N.; AlQaradawi, S. A Study of Low-Temperature CO Oxidation over Mesoporous CuO-TiO 2 Nanotube Catalysts. Catalysts 2017, 7, 129. [CrossRef] 
8. Wang, Y.; Wen, Z.; Zhang, H.; Cao, G.; Sun, Q.; Cao, J. CuO Nanorods-Decorated Reduced Graphene Oxide Nanocatalysts for Catalytic Oxidation of CO. Catalysts 2016, 6, 214. [CrossRef]

9. Zhang, X.; Zhan, Z.; Li, Z.; Di, L. Thermal Activation of CuBTC MOF for CO Oxidation: The Effect of Activation Atmosphere. Catalysts 2017, 7, 106. [CrossRef]

10. Stahl, A.; Wang, Z.; Schwämmle, T.; Ke, J.; Li, X. Novel Fe-W-Ce Mixed Oxide for the Selective Catalytic Reduction of $\mathrm{NO}_{x}$ with $\mathrm{NH}_{3}$ at Low Temperatures. Catalysts 2017, 7, 71. [CrossRef]

11. Qi, C.; Bao, W.; Wang, L.; Li, H.; Wu, W. Study of the $\mathrm{V}_{2} \mathrm{O}_{5}-\mathrm{WO}_{3} / \mathrm{TiO}_{2}$ Catalyst Synthesized from Waste Catalyst on Selective Catalytic Reduction of $\mathrm{NO}_{x}$ by $\mathrm{NH}_{3}$. Catalysts 2017, 7, 110. [CrossRef]

12. Zhang, Y.; Kumar Megarajan, S.; Xu, X.; Lu, J.; Jiang, H. Catalytic Abatement of Nitrous Oxide Coupled with Ethane Oxydehydrogenation over Mesoporous $\mathrm{Cr} / \mathrm{Al}_{2} \mathrm{O}_{3}$ Catalyst. Catalysts 2017, 7, 137. [CrossRef]

13. Zheng, X.; Zhang, R.; Bai, F.; Hua, C. Catalytic Decomposition of $\mathrm{N}_{2} \mathrm{O}$ over $\mathrm{Cu}-\mathrm{Zn} / \mathrm{ZnAl}_{2} \mathrm{O}_{4}$ Catalysts. Catalysts 2017, 7, 166. [CrossRef]

14. Zhang, R.; Hua, C.; Wang, B.; Jiang, Y. $\mathrm{N}_{2} \mathrm{O}$ Decomposition over $\mathrm{Cu}-\mathrm{Zn} / \gamma-\mathrm{Al}_{2} \mathrm{O}_{3}$ Catalysts. Catalysts 2016, 6, 200. [CrossRef]

15. Truppi, A.; Petronella, F.; Placido, T.; Striccoli, M.; Agostiano, A.; Curri, M.; Comparelli, R. Visible-Light-Active $\mathrm{TiO}_{2}$-Based Hybrid Nanocatalysts for Environmental Applications. Catalysts 2017, 7, 100. [CrossRef]

16. Yan, Z.; He, J.; Guo, L.; Li, Y.; Duan, D.; Chen, Y.; Li, J.; Yuan, F.; Wang, J. Biotemplated Mesoporous $\mathrm{TiO}_{2} / \mathrm{SiO}_{2}$ Composite Derived from Aquatic Plant Leaves for Efficient Dye Degradation. Catalysts 2017, 7, 82. [CrossRef]

17. Hayashi, M.; Ochiai, T.; Tago, S.; Tawarayama, H.; Hosoya, T.; Yahagi, T.; Fujishima, A. Influence of Dissolved Ions on the Water Purification Performance of $\mathrm{TiO}_{2}$-Impregnated Porous Silica Tubes. Catalysts 2017, 7, 158. [CrossRef]

18. Liu, J.; Li, Y.; Ke, J.; Wang, Z.; Xiao, H. Synergically Improving Light Harvesting and Charge Transportation of $\mathrm{TiO}_{2}$ Nanobelts by Deposition of $\mathrm{MoS}_{2}$ for Enhanced Photocatalytic Removal of $\mathrm{Cr}(\mathrm{VI})$. Catalysts 2017, 7, 30. [CrossRef]

19. Lee, J.; Jo, W.-K. Three-Dimensional $\mathrm{TiO}_{2}$ Structures Incorporated with Tungsten Oxide for Treatment of Toxic Aromatic Volatile Compounds. Catalysts 2017, 7, 97. [CrossRef]

20. Tian, H.; Wan, C.; Xue, X.; Hu, X.; Wang, X. Effective Electron Transfer Pathway of the Ternary TiO $2 / \mathrm{RGO} / \mathrm{Ag}$ Nanocomposite with Enhanced Photocatalytic Activity under Visible Light. Catalysts 2017, 7, 156. [CrossRef]

21. Shu, H.-Y.; Chang, M.-C.; Tseng, T.-H. Solar and Visible Light Illumination on Immobilized Nano Zinc Oxide for the Degradation and Mineralization of Orange G in Wastewater. Catalysts 2017, 7, 164.

22. Meng, Y.; Luo, W.; Xia, S.; Ni, Z. Preparation of Salen-Metal Complexes (Metal = Co or Ni) Intercalated ZnCr-LDHs and Their Photocatalytic Degradation of Rhodamine B. Catalysts 2017, 7, 143. [CrossRef]

23. Pang, D.; Gao, J.; Ouyang, F.; Zhu, R.; Xie, C. Ion-Exchange of $\mathrm{Cu}^{2+}$ Promoted Layered Perovskite $\mathrm{K}_{2} \mathrm{La}_{2} \mathrm{Ti}_{3} \mathrm{O}_{10}$ for Photocatalytic Degradation Chlorobenzene under Simulated Solar Light Irradiation. Catalysts 2017, 7, 126. [CrossRef] 